\title{
28 Research Square \\ Physical Rehabilitation: A Gap in Care Following all Types of Breast Cancer Surgery.
}

Deirdre E McGhee ( $\nabla$ dmcghee@uow.edu.au )

University of Wollongong School of Medicine https://orcid.org/0000-0002-8070-2533

Julie R Steele

University of Wollongong Faculty of Science: University of Wollongong Faculty of Science Medicine and Health

\section{Research Article}

Keywords: breast cancer, breast reconstruction; mastectomy, breast conserving surgery, physical sideeffects, physical rehabilitation, education

Posted Date: February 15th, 2021

DOl: https://doi.org/10.21203/rs.3.rs-220536/v1

License: (c) (i) This work is licensed under a Creative Commons Attribution 4.0 International License. Read Full License 


\section{Abstract}

Purpose: To investigate the access to and content of physical rehabilitation received by women after different types of breast cancer surgery.

Methods: On-line survey of 632 Australia women (59.8 years SD 9.6) grouped according to their last reported breast cancer surgery: (i) breast conserving surgery (BCS; $n=228)$, (ii) mastectomy ( $n=208$; MAST), and (iii) breast reconstruction (BRS; $n=196$ ). Respondents retrospectively reported the physical rehabilitation education and treatment they received for six physical side-effects. Chi square of analysis of the percentage of respondents who received any form of physical rehabilitation for each physical sideeffect amongst the three groups. Tabulation of the percentage of the entire cohort $(n=632)$ that had lymph nodes removed, post-operative complications, or pre-existing musculoskeletal issues who received any form of physical rehabilitation as part of standard post-operative care.

Results: No significant difference was found in the percentage of respondents who received any form of physical rehabilitation across the three groups, except for the physical side-effects of lymphoedema and breast support issues. Substantial variation was found in the percentage that received physical rehabilitation across the different physical side-effects. Physical rehabilitation for shoulder issues and lymphoedema was received by $75 \%$ and $70 \%$ of respondents respectively as part of standard care, compared to scar and torso issues and physical discomfort disturbing sleep, where less than $50 \%$ received any form of physical rehabilitation.

Conclusion: Access to physical rehabilitation is poor following all types of breast cancer surgery, with gaps in the physical rehabilitation provided for specific physical side-effects.

\section{Introduction}

The physical side-effects of breast cancer surgery can provoke major long-term health and quality of life issues for many women following breast cancer surgery [1-13]. In fact, up to $60 \%$ of women report moderate-to-very-high incidence and severity scores for physical side-effects across multiple body regions, 6 months following all types of breast cancer surgery. These physical side-effects are perceived to limit the ability of up to $60 \%$ of women to participate in physical activity and resume pre-diagnosis work, sport, and daily tasks [14]. Women who have had lymph nodes removed, post-operative complications, or pre-existing physical issues before surgery tend to suffer from more frequent and severe physical side-effects [15-21].

Targeted and early intervention physical rehabilitation and education have been found to be effective in alleviating or resolving many of the physical side-effects associated with breast cancer surgery and treatment [3, 21-36]. Only a few studies, however, have investigated the translation of this physical rehabilitation research into clinical practice. The authors of these studies have reported substantial variation in the percentage of women who received physical rehabilitation treatment and education. For example, after mastectomy and breast conserving surgery, $82 \%$ of women reported that they were 
provided with information on shoulder and arm exercises, but less than $50 \%$ of these women received this information from a physiotherapist [17]. More than $90 \%$ of women with metastatic breast cancer who had either a mastectomy or breast conserving surgery were found to have physical impairments that would, at least in part, be ameliorated by standard rehabilitation measures, and yet less than a third of these women received any rehabilitation treatment [37]. After breast reconstuction surgery, less than $50 \%$ of women reported that they were referred to physiotherapy [26]. This research suggests that translation of physical rehabilitation research into clinical practice is limited and might vary after different types of breast cancer surgery. Access to physical rehabilitation within clinical practice following different types of breast cancer surgery, however, is yet to be systematically investigated. Although the need for physical rehabilitation for shoulder issues after breast conserving surgery might be less than after mastectomy and reconstructive surgery, the reported similarity in incidence and severity of most of the other physical side-effects across all types of breast cancer surgery $[3,14]$ suggests that the need for physical rehabilitation for many other physical side-effects would be similar.

Most physical rehabilitation research following breast cancer surgery has focused on the physical sideeffects related to shoulder issues and lymphoedema [3, 21-30, 35]. Physical side-effects relating to breast support, scar, or torso issues or physical discomfort disturbing sleep have not commonly been investigated. A high percentage of women, however, report experiencing a moderate-to-very-high incidence and severity of these issues at 6 and 12 months following all types of breast cancer surgery [14]. We therefore speculate that these physical side-effects are not commonly included in the content of physical rehabilitation education and treatment provided to women in clinical practice, although the content delivered in clinical practice after different types of breast cancer surgery is yet to be investigated.

Greater understanding of the physical rehabilitation provided to women after all types of breast cancer surgery could lead to improvements in its access and content. This, in turn, could limit the duration, progression, and impact of the physical side-effects on physical activity, sport, work, and daily tasks for women following all types of breast cancer surgery. Improved physical recovery could also have positive flow-on effects on the quality of life, financial, and emotional status of women, as well as decrease their risk of cancer reoccurrence through increased levels of physical activity $[3,12,18,21,25,38-40]$. Given the increasing number of women diagnosed with breast cancer, at a younger age [41], and the high 10year survival rate, it is vital that we maximize physical recovery to enable all women to live well with breast cancer.

The aim of the study was to systematically investigate the access to, and content of physical rehabilitation education and treatment provided to women after breast conserving surgery, mastectomy, and breast reconstruction surgery. This will provide insight into the standard of physical rehabilitation care provided to women after different types of breast cancer surgery, determine the access for women who have a higher risk of developing more frequent and severe physical side-effects, and determine whether the commonly experienced physical side-effects are included in rehabilitation programs. We hypothesized that access to physical rehabilitation education or treatment would vary according to the type of breast cancer surgery and that a higher percentage of women would receive physical 
rehabilitation for shoulder issues and lymphedema compared to for scars, torso and breast support issues, and physical discomfort disturbing sleep.

\section{Methods}

\section{Participants}

Women who had previously had any type of breast cancer surgery were invited to complete an anonymous online survey advertised on breast cancer specific websites across Australia (Breast Cancer Network Australia, Register4, Reclaim Your Curves, and local breast cancer support groups). Consent was provided by clicking an "I agree" button after the Participant Information Sheet. The study was approved by the University Human Research Ethics Committee approved (HE15/453).

\section{On-line survey}

Respondents retrospectively reported whether they received any form of physical rehabilitation education or treatment (YES/NO) for six physical side-effects (scars, shoulder, or torso issues (i.e. pain, decreased range-of-motion, or muscle strength), lymphedema, sleep discomfort, and bra discomfort). Examples of various forms of education/treatment were provided as a guide (e.g. exercises checked or demonstrated in follow-up treatment sessions by a health professional, a pamphlet/handout of exercises provided, instructions with no written instructions, no information, or treatment provided). A YES response was recorded if any form of education or treatment was ticked and a NO response was recorded for "no information or treatment provided'. Respondents who had an autologous breast reconstruction were also asked whether they received any education/treatment for any donor site issues. The physical side-effects were determined from previous research of commonly reported physical side-effects $[14,18]$, previous physical rehabilitation intervention studies $[3,21,22,24]$, and semi-structured interviews with women who had breast cancer surgery $(n=12)$ and clinicians treating women with breast cancer $(n=12)$.

Respondents were then asked whether their education/treatment was provided as part of standard care, sourced independently, or not given at all. Participant characteristics of age, cancer surgery and treatments, and whether they had lymph nodes removed, post-operative complications, or pre-existing musculoskeletal issues were also collected. Face validity was conducted by Breast Cancer Network Australia, Register4, regional breast cancer support groups, three clinicians, and three women with breast cancer. The survey took approximately 10 minutes to complete and was open for 10 months (July 2017 to April 2018). It was published on Qualtrics (v0217; Provo, UT) and of the 729 women who visited the link to the site, 625 completed the survey ( $85.7 \%$ completion rate).

\section{Statistics}

The respondents were grouped according to their last reported type of breast cancer surgery; (i) breast reconstruction surgery (BRS), (ii) mastectomy (MAST), or (iii) breast conserving surgery (BCS). The percentage of women who reported "YES" to receiving any form of education/treatment for each of the physical side-effects was tabulated and compared amongst the three groups using Chi square tests. The 
percentage of the entire cohort $(n=632)$ that had lymph nodes removed, post-operative complications, or pre-existing musculoskeletal issues who received any form of physical rehabilitation as part of standard post-operative care or sourced it independently was also tabulated. All statistical tests were conducted using SPSS Statistics v26.0 for Windows (IBM® Inc., Armonk, USA) with the alpha level set at $P<0.05$.

\section{Results}

\section{Participants}

Characteristics of the 632 respondents are displayed in Table 1. There were no significant differences amongst the groups except for the mean age, which was significant younger in the BRS group compared to the MAST and BCS groups and post-operative complications, which were higher in the MAST group compared to the BRS and BCS groups. 
Table 1

Participant characteristics $(n=632)$.

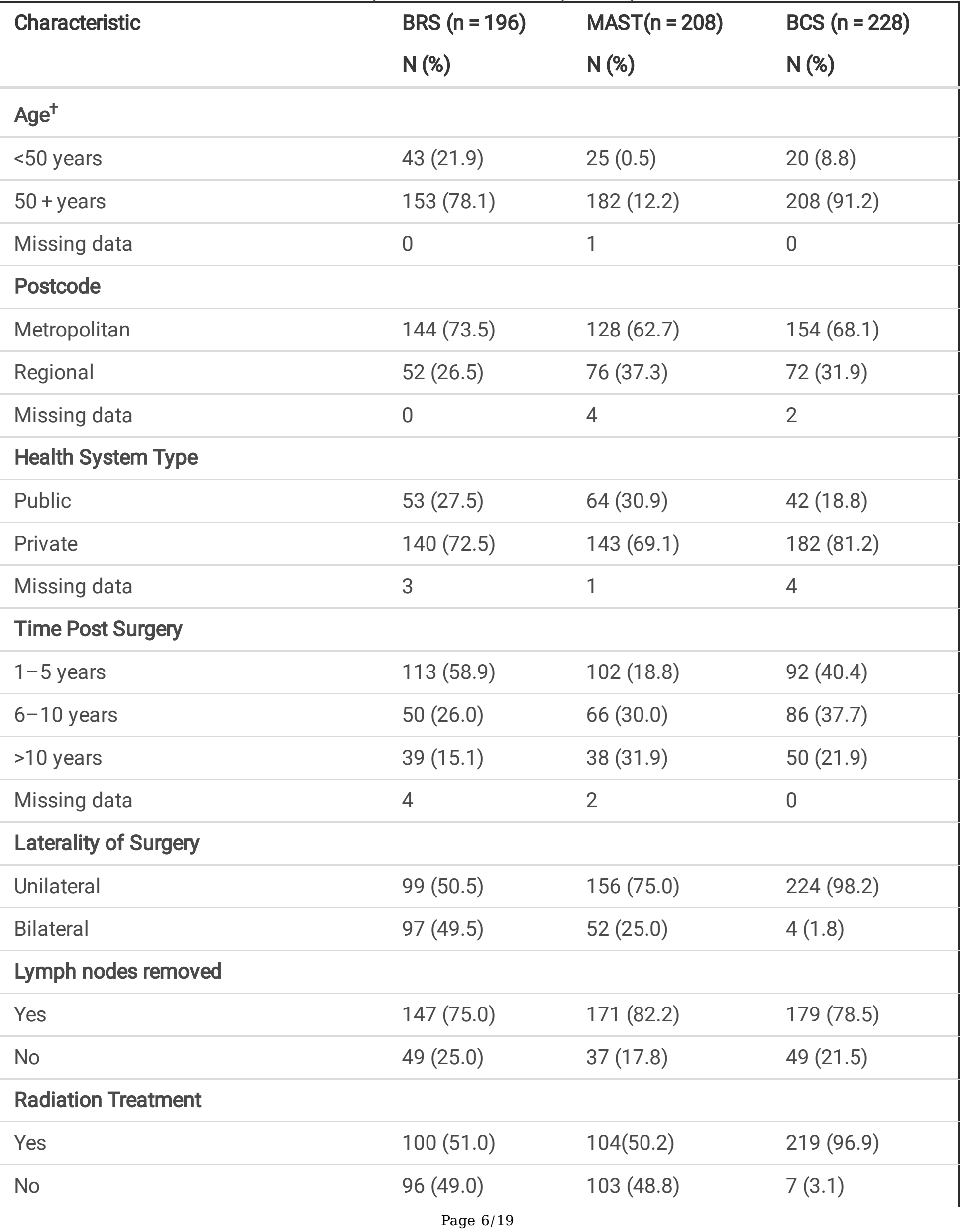




\begin{tabular}{|c|c|c|c|}
\hline \multirow[t]{2}{*}{ Characteristic } & BRS $(n=196)$ & MAST $(n=208)$ & $\operatorname{BCS}(n=228)$ \\
\hline & $N(\%)$ & $\mathbf{N}(\%)$ & $N(\%)$ \\
\hline Missing data & 0 & 1 & 2 \\
\hline \multicolumn{4}{|c|}{ Post-operative complication* } \\
\hline Yes & $94(48.0)$ & $126(60.6)$ & $93(40.8)$ \\
\hline No & $102(52.0)$ & $82(39.4)$ & $135(59.2)$ \\
\hline \multicolumn{4}{|c|}{ Type of Breast Reconstruction } \\
\hline Implant & \multicolumn{3}{|l|}{$99(50.5)$} \\
\hline Autologous & \multicolumn{3}{|l|}{$97(49.5)$} \\
\hline \multicolumn{4}{|c|}{ Timing of Breast Reconstruction } \\
\hline Same time & \multicolumn{3}{|l|}{$58(29.6)$} \\
\hline Delayed & \multicolumn{3}{|l|}{$138(70.4)$} \\
\hline \multicolumn{4}{|c|}{$\begin{array}{l}\text { BRS: breast reconstruction surgery; MAST: mastectomy; BCS: breast conservation surgery. } \\
\text { t The breast reconstruction surgery group overall were significantly younger than both the } \\
\text { mastectomy and breast conserving surgery group }(p<0.001) \text {. }\end{array}$} \\
\hline \multicolumn{4}{|c|}{ * Includes infections, seromas, necrosis, and other identified complications. } \\
\hline
\end{tabular}

\section{Access to physical rehabilitation}

The percentage of respondents who reported "YES" to having received any form of physical rehabilitation education and treatment was not significantly different amongst the groups for any of the physical sideeffects except lymphedema and breast support issues (Table 2). A significantly lower percentage of the BRS group, who had an immediate breast reconstruction, received physical rehabilitation for breast support issues compared to those who had a delayed breast reconstruction (Table 3). 
Table 2

Percentage of respondents who reported to have received any form of physical rehabilitation education/treatment for each physical side-effect overall and for each of the surgery groups.

\begin{tabular}{|c|c|c|c|c|}
\hline \multicolumn{5}{|c|}{ \% Respondents who received treatment } \\
\hline \multirow[t]{2}{*}{ Physical Side Effect } & Overall & BRS & MAST & BCS \\
\hline & $N=632$ & $N=196$ & $N=208$ & $N=228$ \\
\hline Scar issues ${ }^{1}$ & 45.5 & 53.2 & 47.3 & 37.5 \\
\hline Shoulder issues ${ }^{1}$ & 74.8 & 75.8 & 82.7 & 66.5 \\
\hline Torso issues ${ }^{1}$ & 43.4 & 46.2 & 48.1 & 36.6 \\
\hline Lymphedema & 66.7 & $24.6^{*}$ & 86.1 & 85.3 \\
\hline Breast support issues & 68.4 & 66.7 & 86.5 & $53.1^{\star}$ \\
\hline Physical sleep discomfort & 25.6 & 27.4 & 19.7 & 29.5 \\
\hline Donor site issues ${ }^{2}$ & $\mathrm{n} / \mathrm{a}$ & 56.8 & $\mathrm{n} / \mathrm{a}$ & $\mathrm{n} / \mathrm{a}$ \\
\hline $\begin{array}{l}\text { BRS: breast reconstruction } \\
{ }^{1} \text { Scar, shoulder, and torso } \\
{ }^{2} \text { Donor site pain was only } \\
\text { reconstructions }(\mathrm{N}=95) \text { an }\end{array}$ & $\begin{array}{l}\text { T: mastect } \\
\text { pain and } \\
\text { the breast } \\
\text { ould not be }\end{array}$ & $\begin{array}{l}\text { 3CS: brea } \\
\text { sed rang } \\
\text { struction } \\
\text { sared am }\end{array}$ & $\begin{array}{l}\text { Iservation } \\
\text { otion or } \mathrm{m} \\
\text { ry group } \mathrm{fo} \\
\text { the three } \mathrm{g}\end{array}$ & $\begin{array}{l}\text { sy. } \\
\text { strength. } \\
\text { ologous } \\
\text { s. }\end{array}$ \\
\hline \multicolumn{5}{|c|}{$\begin{array}{l}\text { * Statistically significant difference between groups (i.e. a higher percentage of respondents received } \\
\text { treatment in both other groups). }\end{array}$} \\
\hline
\end{tabular}


Table 3

Percentage of BRS group $(n=196)$ divided into sub-groups of Immediate versus Delayed Breast Reconstruction Surgery who reported to have received any form of physical rehabilitation education/treatment for each physical side-effect.

\begin{tabular}{|c|c|c|}
\hline & $\begin{array}{l}\% \text { BRS group who r } \\
\text { education/treatmer }\end{array}$ & hysical rehabilitation \\
\hline \multirow[t]{2}{*}{ Physical Side Effect } & Immediate surgery & Delayed surgery \\
\hline & $N=58$ & $N=138$ \\
\hline Scar issues ${ }^{1}$ & 53.6 & 53.1 \\
\hline Shoulder issues $^{1}$ & 73.2 & 76.9 \\
\hline Torso issues ${ }^{1}$ & 46.4 & 46.2 \\
\hline Lymphedema & 17.2 & 27.7 \\
\hline Breast support issues & $50.0 *$ & 73.8 \\
\hline $\begin{array}{l}\text { Physical sleep } \\
\text { discomfort }\end{array}$ & 25.0 & 28.5 \\
\hline Donor site issues & 43.3 & 43.1 \\
\hline \multicolumn{3}{|c|}{ BRS: breast reconstruction surgery. } \\
\hline \multicolumn{3}{|c|}{${ }^{1}$ Scar, shoulder and torso issues include pain and decreased range of motion or muscle strength. } \\
\hline
\end{tabular}

Less than $40 \%$ of respondents received any form of physical rehabilitation education and treatment as part of their standard care. Furthermore, the percentage of respondents who sourced their physical rehabilitation independently for each physical side-effect was equivalent or greater to the percentage who received it as part of standard care (Table 4). Less than $40 \%$ of the respondents who had lymph nodes removed, post-operative complications, or pre-existing musculoskeletal issues received any form of physical rehabilitation education or treatment as part of their standard care (Table 5). 
Table 4

Percentage of respondents $(N=632)$ who reported to have received their physical rehabilitation education/treatment as part of their standard care or sought it independently for each of the physical side-effects.

\begin{tabular}{|c|c|c|}
\hline $\begin{array}{l}\text { Physical side } \\
\text { effect }\end{array}$ & $\begin{array}{l}\text { Education/ treatment provided as } \\
\text { standard care }(\%)\end{array}$ & $\begin{array}{l}\text { I sought additional education/ treatment } \\
\text { on my own (\%) }\end{array}$ \\
\hline Scar issues ${ }^{1}$ & 29.1 & 23.6 \\
\hline $\begin{array}{l}\text { Shoulder } \\
\text { issues }^{1}\end{array}$ & 29.9 & 36.7 \\
\hline Torso issues $^{1}$ & 16.5 & 28.0 \\
\hline Lymphedema & 35.8 & 34.2 \\
\hline $\begin{array}{l}\text { Breast support } \\
\text { issues }\end{array}$ & 23.9 & 44.3 \\
\hline $\begin{array}{l}\text { Sleep } \\
\text { discomfort }\end{array}$ & 13.8 & 21.5 \\
\hline $\begin{array}{l}\text { Donor site } \\
\text { pain }\end{array}$ & 23.8 & 33.7 \\
\hline \multicolumn{3}{|c|}{$\begin{array}{l}{ }^{1} \text { Scar, shoulder and torso issues include pain, decreased range of motion or muscle strength. } \\
2 \text { Donor site pain was only completed by the breast reconstruction surgery group for autologous } \\
\text { reconstructions }(\mathrm{N}=95) \text {. }\end{array}$} \\
\hline
\end{tabular}


Table 5

Percentage of respondents $(N=632)$ who reported to have had lymph nodes removed, post-operative complications, or pre-existing physical problems and

$\begin{array}{lllll}\text { Characteristic } & \begin{array}{l}\text { Standard } \\ \text { Care N (\%) }\end{array} & \begin{array}{l}\text { Sourced treatment } \\ \text { independently N (\%) }\end{array} & \begin{array}{l}\text { No treatment } \\ \text { received N (\%) }\end{array} & \begin{array}{l}\text { Not } \\ \text { applicable }\end{array} \\ \mathbf{N}(\%)\end{array}$

\section{Lymph nodes} removed

YES $(\mathrm{N}=497)$
Pre-existing
musculoskeletal
issues

Shoulder/Torso $(\mathrm{n}=$

70)

$27(38.6)$

$27(38.6)$

$14(20.0)$

$2(2.9)$

\section{Post-operative complications*}

YES $(\mathrm{N}=272)$

$85(31.3)$

$115(42.3)$

$68(25.0)$

$4(1.5)$

received any form of physical rehabilitation education/treatment as part of standard care, sourced independently, or who received no education/treatment.

\section{Content of physical rehabilitation}

Considerable variation was found in the percentage of the entire cohort who received any form of physical rehabilitation according to each physical side-effect. More than $70 \%$ of respondents received physical rehabilitation for shoulder issues but less than $50 \%$ received anything for scar and torso issues or physical discomfort disturbing sleep (Table 2).

\section{Discussion}

Access to physical rehabilitation education and treatment for women following breast cancer surgery was found to be similar irrespective of the type of breast cancer surgery, except for lymphedema and breast support issues. Substantial variation was found in the access to physical rehabilitation depending on each specific physical side-effect. Because most respondents did not receive any form of physical rehabilitation education or treatment as part of their standard care, we deem that physical rehabilitation is a gap in care following all types of breast cancer surgery. The implications of this are discussed below.

Consistent with previous research, physical rehabilitation was found to be underutilized by women after breast cancer surgery $[17,28,42]$. The percentage of respondents who received any form of physical rehabilitation education or treatment for shoulder issues was similar to previous research [17]. No previous research, however, had measured access to any form of physical rehabilitation for the other physical side-effects. 
The significantly lower percentage of the BRS group (25\%) who received any form of physical rehabilitation for lymphedema compared to the MAST (86\%) and BCS (85\%) groups was attributed to previous research that reported the risk of lymphedema to be lower after breast reconstructive surgery [43, 44] compared to mastectomy and breast conserving surgery. Decreased risk, however, does not mean that women cannot develop lymphedema after breast reconstructive surgery. It is therefore concerning that only $17 \%$ of the BRS group who had an immediate breast reconstruction $(n=58)$ received any education or treatment for lymphedema (Table 3), even though $67.2 \%$ of these women also had lymph nodes removed. Only a third of the entire cohort who had lymph nodes removed $(n=497)$ received any information about lymphedema as part of their standard care (Table 5), yet the need for lymphedema education/treatment by these women is evident by the equivalent percentage who sourced their own lymphedema education/treatment (Table 4). Lymphedema has high economic cost to both the health system and individuals and negatively impacts long-term health and quality of life [24, 46-49]. Considering early intervention is vital to effectively manage lymphedema $[17,19,24,45]$ and providing education to allow for early intervention has a relatively low cost, the gap in care for lymphedema must urgently be filled, particularly given the increasing number of women who are electing to have an immediate breast reconstruction surgery $[50,51]$.

Contrary to our hypothesis, the only other significant difference in the access to physical rehabilitation for women following different types of breast cancer surgery was for breast support issues (Table 2). The significantly lower percentage of the BCS group ( 50\%) who received any form of education/treatment for breast support issues compared to the MAST ( 85\%) and BRS group ( 66\%) and the significantly lower percentage of the BRS group who had an immediate breast reconstruction ( $50 \%)$ compared to those who had a delayed breast reconstruction $(\sim 75 \%)$ does not align with need for education/treatment for breast support issues. Approximately $60 \%$ of women experience breast support issues of a moderateto-very high incidence and severity 12 -months after all types of breast cancer surgery $[14,18,52]$. Importantly, breast support issues are perceived to be the third highest barrier to physical activity after breast cancer surgery [53-55] (Table 3). The need for education/treatment for breast support issues is supported by the nearly two-fold number of respondents who sourced their own education/treatment for breast support issues compared to that provided by standard care. It is also concerning for the BCS group because $97 \%$ also had radiation treatment, which is assocated with scarring and breast edema, which are known to exacerbate breast support issues [20, 49, 56-59]. Although the underlying mechanisms of breast support issues experienced by women varies according to the different types of breast cancer surgery $[14,52]$, the need for education and guidance on how to find a comfortable, supportive, correctly fitted bra (and prosthesis) is an essential component of any physical rehabilitation program following all types of breast cancer surgery.

Women who have a higher risk of developing more severe and frequent physical side-effects following breast cancer surgery are especially in need of physical rehabilitation education and treatment [15-19]. Pain, mobility, and strength issues associated with scars and the shoulder are likely sequelae of seromas and delayed healing of surgical scars secondary to infection or tissue necrosis. Yet, less than a third of the respondents who had post-operative complications $(n=272)$ received any form of physical 
rehabilitation as part of their standard care for their shoulder or scar issues to help them to prepare for or manage these side-effects (Table 4). The same scenario occurred for respondents who had pre-existing physical problems in their shoulder or torso region, with less than $40 \%$ receiving any physical rehabilitation for their shoulder as part of their standard care. The equivalent percentage ( $40 \%)$ who sourced their own treatment for these issues is evidence of the need these women have for physical rehabilitation to manage these side-effects. Pre-operative questioning for any pre-existing physical problems and greater follow-up of women who experience post-operative complications is required to ensure that the women who are at greater risk of developing more frequent and severe physical sideeffects have access to physical rehabilitation as part of their standard post-operative care. This could limit the duration, progression, and impact of these physical side effects on physical activity, sport, and daily tasks.

Consistent with our second hypothesis, the content of the physical rehabilitation provided to women following all types of breast cancer surgery varied according to each side-effect and was less for scar, torso and breast support issues, and physical discomfort disturbing sleep compared to shoulder issues and lymphedema. Of concern, less than $50 \%$ of respondents received any form of physical rehabilitation education/treatment for scar or torso issues and only $25 \%$ received any guidance on how to get into a safe and comfortable position to enable good sleep after their surgery (Table 2). Again, the need for physical rehabilitation for these issues was evident by high percentage of women who independently sourced relevant information about physical rehabilitation education/treatment for scar, torso, and sleep issues compared to the percentage who received it standard care (Table 5). Scar issues that have an moderate to very high incidence and severity affect over $30 \%$ of women 6 months following all types of breast cancer surgery and can limit shoulder and torso range of motion and cause bra discomfort on underlying scars $[14,52]$. Over $40 \%$ of women report difficulty finding a sleeping position in order to get a good night's sleep at 6 months post-surgery [14]. Guidance on how to get physically comfortable to enable good sleep is vital to promote tissue healing, and mental and physical health. Good sleep also limits fatigue, which is a known barrier to physical activity [53]. It is therefore vital that physical rehabilitation education and treatment programs for women following breast cancer surgery include all of the commonly reported physical side-effects, particularly because women report a lack of awareness and knowledge of how to manage these side-effects makes them more distressing and debilitating [60-62].

The content of physical rehabilitation education and treatment following autologous breast reconstructions was also lacking in relation to donor site issues because only one in two respondents received any physical rehabilitation for their donor site. Yet pain and decreased mobility and muscle strength in the region of the donor site of a moderate to very high incidence and severity has been reported by $20 \%$ of women 6 -months after autologous breast reconstruction surgery [18]. Strategies to maximize the physical recovery of the donor site should also be fundamental content included in the physical rehabilitation education and treatment provided to women following autologous breast reconstructions.

\section{Study Limitations}


A limitation of the study is that no time limit was placed on the time since surgery (mean $6.7 \pm 6.0$ years (range: 0-46 years). It is therefore possible that the physical rehabilitation following surgery over this period may have changed, just as surgical techniques have changed. Although this study provides insight into the access to physical rehabilitation following different types of breast cancer surgery and which physical side-effects are commonly included, it does not provide any detail on the quality or patient perceptions of this education and treatment. The quality and patient perceptions of education and treatment delivered in the form of a pamphlet are likely to differ compared to follow-up sessions with a health professional, where exercises are demonstrated, checked, and progressed. Further research is therefore recommended to investigate the content of physical rehabilitation education and treatment both quantitatively and qualitatively, received by women following all types of breast cancer surgery.

\section{Conclusion}

Access to physical rehabilitation is poor following all types of breast cancer surgery, even for women who have a higher risk of developing more frequent and severe side-effects. Gaps exist in the physical rehabilitation provided for specific physical side-effects, especially scar and torso issues and physical discomfort disturbing sleep. There is an urgent need to improve the physical rehabilitation of women after all types of breast cancer surgery to enable women to maximize their physical recovery and live well with breast cancer

\section{Declarations}

The authors have nothing to declare.

\section{Funding}

The study was funded by the University of Wollongong, Faculty of Science, Medicine and Health.

\section{Conflicts of interest/Competing interests (include appropriate disclosures)}

The authors have no conflicts of interest or competing interests.

\section{Acknowledgements.}

The authors would like to thank Breast Cancer Network Australia, Register4, and breast cancer support groups (including Reclaim Your Curves) for their support of this project and Jodi Steel, for her passion for this project and invaluable contribution as a consumer advocate.

\section{References}

1. Zomkowski K, Cruz de Souza B, Pinheiro da Silva F, Moreira GM et al (2018) Physical symptoms and working performance in female breast cancer survivors: a systematic review. Disabil Rehabil 40(13):1485-1493. doi:10.1080/09638288.2017.1300950 
2. van Huizum MA, Hoornweg MJ, de Ruiter N, Oudenhoven E et al (2016) Effect of latissimus dorsi flap breast reconstruction on the strength profile of the upper extremity. J Plast Surg Hand Surg 50(4):202-207. doi:10.3109/2000656X.2016.1151436

3. McNeely ML, Binkley JM, Pusic AL, Campbell KL et al (2012) A prospective model of care for breast cancer rehabilitation: postoperative and postreconstructive issues. [Review] Cancer 118(8 suppl):2226-2236. doi:10.1002/cncr.27468

4. Sagen A, Kaaresen R, Sandvik L, Thune I et al (2014) Upper limb physical function and adverse effects after breast cancer surgery: A prospective 2.5-year follow-up study and preoperative measures. Arch Phys Med Rehabil 95(5):875-881. doi:10.1016/j.apmr.2013.12.015

5. Levangie PK, Drouin J (2009) Magnitude of late effects of breast cancer treatments on shoulder function: a systematic review. Breast Cancer Res Treat 116(1):1-15. doi:10.1007/s10549-008-0246-4

6. Black KZ, Johnson LS, Samuel-Hodge CD, Gupta L et al (2018) Perceived barriers and preferred components for physical activity interventions in African-American survivors of breast or endometrial cancer with type 2 diabetes: the S.U.C.C.E.S.S. framework. Support Care Cancer 26(1):231-240. doi:10.1007/s00520-017-3839-9

7. Blackburn NE, Mc Veigh JG, Mc Caughan E, Wilson IM (2018) The musculoskeletal consequences of breast reconstruction using the latissimus dorsi muscle for women following mastectomy for breast cancer: a critical review. Eur J Cancer Care 27(2):e12664. doi:10.1111/ecc.12664

8. Nilsson M, Olsson M, Wennman-Larsen A, Petersson LM et al (2011) Return to work after breast cancer: women's experiences of encounters with different stakeholders. Eur J Oncol Nurs 15(3):267274. doi:10.1016/j.ejon.2011.03.005

9. Hayes SC, Rye S, Battistutta D, DiSipio T et al (2010) Upper-body morbidity following breast cancer treatment is common, may persist longer-term and adversely influences quality of life. Health Qual Life Outcomes 8:92. doi:10.1186/1477-7525-8-92

10. Nesvold IL, Reinertsen KV, Fossa SD, Dahl AA (2011) The relation between arm/shoulder problems and quality of life in breast cancer survivors: a cross-sectional and longitudinal study. J Cancer Surviv 5(1):62-72. doi:10.1007/s11764-010-0156-4

11. Miedema B, Hamilton R, Tatemichi S, Thomas-maclean R et al (2008) Predicting recreational difficulties and decreased leisure activities in women 6-12 months post breast cancer surgery. $\mathrm{J}$ Cancer Survivorship 2(4):262-268. doi:10.1007/s11764-008-0068-8

12. Michael YL, Kawachi I, Berkman LF, Holmes MD et al. The persistent impact of breast carcinoma on functional health status - Prospective evidence from the nurses' health study. Cancer. 2000;89(11):2176-2186. doi:10.1002/1097-0142\%2820001201\%2989\%3A11\%3C2176\%3A\%3AAIDCNCR5\%3E3.0.CO\%3B2-6

13. Romero SAD, Li QS, Mao JJ (2017) Factors and barriers associated with changes in physical activity after. cancer diagnosis 35(5_suppl):162-162. doi:10.1200/JC0.2017.35.5_suppl.162

14. McGhee DE, Steele JR (2020) Physical recovery following all types of breast cancer surgery is poor and a barrier to physical activity. Acta Oncol. Submitted for publication, January, 2021 
15. De Oliveira GS Jr, Chang R, Khan SA, Hansen NM et al (2014) Factors associated with the development of chronic pain after surgery for breast cancer: a prospective cohort from a tertiary center in the United States. Breast J 20(1):9-14. doi:10.1111/tbj.12207

16. Paolini G, Amoroso M, Pugliese P, Longo B et al (2014) Functional sequelae following bilateral mastectomy and immediate reconstruction with latissimus dorsi flap: medium-term follow-up. J Plast Surg Hand Surg 48(2):99-103. doi:10.3109/2000656X.2013.812968

17. Dylke ES, Kilbreath K (2015) Current rehabilitation processes do not prevent long-term impairments after treatment for breast cancer in Australia. Australia Fam Physi 44(6):405-409

18. McGhee DE, Steele JR (2020) Physical side-effects following breast reconstructive surgery impact physical function and activity. Support Care Cancer. 2020;May 28. doi: 10.1007/s00520-020-055346. Online ahead of print. doi: 10.1007/s00520-020-05534-6

19. Kibar S, Dalyan Aras M, Unsal Delialioglu S (2017) The risk factors and prevalence of upper extremity impairments and an analysis of effects of lymphoedema and other impairments on the quality of life of breast cancer patients. Eur J Cancer Care (Engl) 26(4):e12433. doi:10.1111/ecc.12433

20. Hidding JT, Beurskens CH, van der Wees PJ, van Laarhoven HW et al (2014) Treatment related impairments in arm and shoulder in patients with breast cancer: a systematic review. PLoS One 9(5):e96748. doi:10.1371/journal.pone.0096748

21. Bruce J, Williamson E, Lait C, Richmond H et al (2018) Randomised controlled trial of exercise to prevent shoulder problems in women undergoing breast cancer treatment: study protocol for the prevention of shoulder problems trial (UK PROSPER). BMJ Open 8(3):e019078. doi:10.1136/bmjopen-2017-019078

22. Chan DN, Lui LY, So WK (2010) Effectiveness of exercise programmes on shoulder mobility and lymphoedema after axillary lymph node dissection for breast cancer: systematic review. J Adv Nurs 66(9):1902-1914. doi:10.1111/j.1365-2648.2010.05374.x

23. McNeely ML, Campbell KL, Ospina M, Rowe BH et al (2010) Exercise interventions for upper-limb dysfunction due to breast cancer treatment. Cochrane Database Syst Rev 16(6):CD005211. doi:10.1002/14651858.CD005211.pub2

24. Hayes SC, Johansson K, Stout N, Prosnitz R et al (2012) Upper-body morbidity after breast cancer: Incidence and evidence for evaluation, prevention and management wiithin a prospective surveillance model of care. Cancer 118(8):2237-2249. doi:10.1002/cncr.27467

25. Tatham B, Smith J, Cheifetz O, Gillespie J et al (2013) The efficacy of exercise therapy in reducing shoulder pain related to breast cancer: a systematic review. Physiother Can 65(4):321-330. doi:10.3138/ptc.2012-06

26. Mazuquin B, Sunemi MMO, MPP ES, Sarian LOZ et al (2020) Current physical therapy care of patients undergoing breast reconstruction for breast cancer: a survey of practice in the United Kingdom and Brazil. Braz J Phys Ther. doi:10.1016/j.bjpt.2020.05.010

27. Schmitz KH, Speck RM, Rye SA, DiSipio T et al (2012) Prevalence of breast cancer treatment sequelae over 6 years of follow-up: the Pulling Through Study. Cancer 118(8 Suppl):2217-2225. 
doi:10.1002/cncr.27474

28. Stubblefield MD (2017) The Underutilization of Rehabilitation to Treat Physical Impairments in Breast Cancer Survivors. PM R 9(9S2):S317-S323. doi:10.1016/j.pmrj.2017.05.010

29. Olsson Moller U, Beck I, Ryden L, Malmstrom M (2019) A comprehensive approach to rehabilitation interventions following breast cancer treatment - a systematic review of systematic reviews. BMC Cancer 19(1):472. doi:10.1186/s12885-019-5648-7

30. Singh B, Spence RR, Steele ML, Sandler CX et al (2018) A systematic review and meta-analysis of the safety, feasibility, and effect of exercise in women with stage II + breast cancer. Arch Phys Med Rehabil 99(12):2621-2636. doi:10.1016/j.apmr.2018.03.026

31. Spence RR, Heesch KC, Brown WJ (2010) Exercise and cancer rehabilitation: a systematic review. Cancer Treat Rev 36(2):185-194. doi:10.1016/j.ctrv.2009.11.003

32. Cheema BS, Kilbreath SL, Fahey PP, Delaney GP et al (2014) Safety and efficacy of progressive resistance training in breast cancer: a systematic review and meta-analysis. Breast Cancer Res Treat 148(2):249-268. doi:10.1007/s10549-014-3162-9

33. De Groef A, Van Kampen M, Dieltjens E, Christiaens MR et al (2015) Effectiveness of postoperative physical therapy for upper-limb impairments after breast cancer treatment: a systematic review. Arch Phys Med Rehabil 96(6):1140-1153. doi:10.1016/j.apmr.2015.01.006

34. Cho Y, Do J, Jung S, Kwon $O$ et al (2016) Effects of a physical therapy program combined with manual lymphatic drainage on shoulder function, quality of life, lymphedema incidence, and pain in breast cancer patients with axillary web syndrome following axillary dissection. Support Care Cancer 24(5):2047-2057. doi:10.1007/s00520-015-3005-1

35. McNeely ML, Campbell KL, Rowe BH, Klassen TP et al (2006) Effects of exercise on breast cancer patients and survivors: a systematic review and meta-analysis. Can Med Ass J 175(1):34-41. doi:10.1503/cmaj.051073

36. Rostkowska E, Bąk M, Samborski W (2006) Body posture in women after mastectomy and its changes as a result of rehabilitation. Adv Med Sci 51(4):287-297

37. Cheville AL, Troxel AB, Basford JR, Kornblith AB (2008) Prevalence and treatment patterns of physical impairments in patients with metastatic breast cancer. J Clin Oncol 26(16):2621-2629. doi:10.1200/JCO.2007.12.3075

38. Nelson JA, Lee IT, Disa JJ (2018) The Functional Impact of Breast Reconstruction: An Overview and Update. Plast Reconstr Surg Glob Open 6(3):e1640. doi:10.1097/GOX.0000000000001640

39. Blanchard CM, Courneya KS, Stein K (2008) American Cancer Society's SCS, II. Cancer survivors' adherence to lifestyle behavior recommendations and associations with health-related quality of life: results from the American Cancer Society's SCS-II. J Clin Oncol 26(13):2198-2204. doi:10.1200/JC0.2007.14.6217

40. Lof M, Bergstrom K, Weiderpass E (2012) Physical activity and biomarkers in breast cancer survivors: a systematic review. Maturitas 73(2):134-142. doi:10.1016/j.maturitas.2012.07.002 
41. American Cancer Society's SCS, II. Breast Cancer Facts and Figs. 2017-2018.. Breast Cancer Facts and Figs. 2017-2018. https://www.cancer.org/content/dam/cancer-org/research/cancer-facts-andstatistics/breast-cancer-facts-and-figures/breast-cancer-facts-and-figures-2017-2018.pdf. (accessed October, 2020)

42. Cheville AL, Beck LA, Petersen TL, Marks RS et al (2009) The detection and treatment of cancerrelated functional problems in an outpatient setting. Support Care Cancer 17(1):61-67. doi:10.1007/s00520-008-0461-x

43. Lopez Penha TR, Voogd AC, Heuts EM, ljsbrandy C et al (2014) Reduced prevalence of lymphedema in patients with reconstructive breast surgery. Breast J 20(6):671-673. doi:10.1111/tbj.12342

44. Siotos C, Sebai ME, Wan EL, Bello RJ et al (2018) Breast reconstruction and risk of arm lymphedema development: a meta-analysis. J Plast Reconstr Aesthet Surg 71(6):807-818.

doi:10.1016/j.bjps.2018.01.012

45. Stout Gergich NL, Pfalzer LA, McGarvey C, Springer B et al (2008) Preoperative assessment enables the early diagnosis and successful treatment of lymphedema. Cancer 112(12):2809-2819. doi:10.1002/cncr.23494

46. Stout NL, Binkley JM, Schmitz KH, Andrews K et al (2012) A prospective surveillance model for rehabilitation for women with breast cancer. Cancer 118(8 Suppl):2191-2200

47. DiSipio T, Rye S, Newman B, Hayes S (2013) Incidence of unilateral arm lymphoedema after breast cancer: a systematic review and meta-analysis. The Lancet Oncology 14(6):500-515. doi:10.1016/s1470-2045(13)70076-7

48. Fu M (2009) Breast cancer survivors' experiences of lymphedema-related symptoms. Oncol Nurs Forum 36(3):62. doi:10.1188/10.0NF.E28-E33

49. Smoot B, Wampler M, Topp K (2009) Breast cancer treatments and complications: implications for rehabilitation. Rehabil Oncol 27(3):16-26. doi:10.1097/01893697-200927030-00004

50. Ilonzo N, Tsang A, Tsantes S, Estabrook A et al (2017) Breast reconstruction after mastectomy: A tenyear analysis of trends and immediate postoperative outcomes. Breast 32:7-12. doi:10.1016/j.breast.2016.11.023

51. Hong KY, Son Y, Chang H, Jin US (2018) Trends in breast reconstruction: Implications for the National Health Insurance Service. Arch Plast Surg 45(3):239-245. doi:10.5999/aps.2017.01417

52. Nicklaus KM, Bravo K, Liu C, Chopra D et al (2020) Undergarment needs after breast cancer surgery: a key survivorship consideration. Support Care Cancer 28(8):3481-3484. doi:10.1007/s00520-02005414-z

53. Gho S, Steele JR, Munro B (2010) Is bra discomfort a barrier to exercise for breast cancer patients? J Support Care Cancer 18(6):735-741. doi:10.1007/s00520-009-0707-2

54. McGhee DE, Steele JR (2020) Biomechanics of breast support for active women. Exerc Sport Sci Rev 48(3):99-109. doi:10.1249/JES.0000000000000221

55. Gho SA, Munro BJ, Jones SC, Steele JR (2014) Exercise bra discomfort is associated with insufficient exercise levels among Australian women treated for breast cancer. Support Care Cancer 22(3):721- 
729. doi:10.1007/s00520-013-2027-9

56. Stubblefield MD, Keole N (2014) Upper body pain and functional disorders in patients with breast cancer. Phys Med Rehabil 6(2):170-183. doi:10.1016/j.pmrj.2013.08.605

57. Lash TL, Silliman RL (2000) Patient characteristics and treatments associated with a decline in upper-body function following breast cancer therapy. J Clin Epidem 53:615-622

58. Young-Afat DA, Gregorowitsch ML, van den Bongard DH, Burgmans I et al (2019) Breast edema following breast-conserving surgery and radiotherapy: patient-reported prevalence, determinants, and effect on health-related quality of life. JNCI Cancer Spectr 3(2):pkz011. doi:10.1093/jncics/pkz011

59. Verbelen H, Gebruers N, Beyers T, De Monie AC et al (2014) Breast edema in breast cancer patients following breast-conserving surgery and radiotherapy: a systematic review. Breast Cancer Res Treat 147(3):463-471. doi:10.1007/s10549-014-3110-8

60. Levangie PK, Santasier AM, Stout NL, Pfalzer L (2011) A qualitative assessment of upper quarter dysfunction reported by physical therapists treated for breast cancer or treating breast cancer sequelae. Support Care Cancer 19(9):1367-1378. doi:10.1007/s00520-010-0959-x

61. Rosedale M, Fu MR (2009) Confronting the unexpected: temporal, situational, and attributive dimensions of distressing symptom experience for breast cancer survivors. Oncol Nurs Forum 37(1):E28-E33. doi:10.1188/10.0NF.E28-E33

62. Bender JL, Hohenadel J, Wong J, Katz J et al (2008) What patients with cancer want to know about pain: a qualitative study. J Pain Symptom Manage 35(2):177-187.

doi:10.1016/j.jpainsymman.2007.03.011 